\title{
ethic@ \\ APLICANDO A ÉTICA DO DISCURSO DE APEL: CORRESPONSABILIDADE NA JUSTIÇA CLIMÁTICA GLOBAL
}

\author{
APPLYING APEL'S DISCOURSE ETHICS: \\ CORRESPONSIBILITY IN GLOBAL CLIMATE JUSTICE
}

MILENE CONSENSO TONETTO ${ }^{1}$

(UFSC/Brasil)

\begin{abstract}
RESUMO
O objetivo deste artigo é analisar como Karl-Otto Apel implementa a ética do discurso como uma proposta de ética global ou "macroética planetária". Particularmente, será investigado se essa proposta é relevante e atual para lidar com as implicações éticas globais das mudanças climáticas. A macroética planetária irá exigir uma situação de diálogo e corresponsabilidade para o enfrentamento das mudanças climáticas. Isso irá demandar cooperação internacional entre governos, mas também entre indivíduos, empresas ou corporações para reduzir equitativamente as emissões de GEE o mais rápido possível e garantir políticas socialmente justas.
\end{abstract}

Palavras-chave: Apel; Ética do discurso; Mudança do clima; Justiça.

\section{ABSTRACT}

The aim of this paper is to analyze how Karl-Otto Apel implements discourse ethics as a proposal for global ethics or "planetary macroethics". In particular, it will be investigated whether this proposal is relevant and current to deal with the global ethical implications of climate change. Planetary macroethics will demand a situation of dialogue and co-responsibility to face climate change. This will require international cooperation between governments, but also between individuals, companies, corporations to equitably reduce GHG emissions as quickly as possible and ensure socially just policies.

Keywords: Apel; Discourse ethics; Climate change; Justice.

\section{Introdução}

Desde o final da década de 1960, o filósofo Karl-Otto Apel trabalhou na fundamentação e implementação de uma concepção de ética global. De acordo com Apel, foi ele quem defendeu, pela primeira vez no século $X X$, que a "nossa responsabilidade ética tinha que lidar com a extensão planetária e o risco dos efeitos colaterais da ciência e tecnologia" (APEL, 
$2000 b, 138)$. Apel usou o conceito de "macroética planetária" para se referir às dimensões da evolução cultural, a saber, as intervenções tecnológicas na natureza e a interação social (APEL, 1996, 278; 2000a, 407). Sendo assim, pode-se constatar em seus escritos a preocupação com diversos temas relacionados à ética global, a saber, as ameaças do armamento nuclear e da crise ecológica e o sistema global de comércio injusto que resulta em exploração e empobrecimento de milhares de pessoas. Para ele, esses problemas não eram apenas desafios éticos, mas também problemas filosóficos que demandavam uma atenção especial. Eles são causados por ações coletivas e produzem uma situação global que exige uma nova ética de responsabilidade compartilhada e não podem ser resolvidos pelos modelos tradicionais de ética, tais como, as teorias do contrato social, limitadas pela racionalidade estratégica do interesse próprio. Desse modo, a proposta de Apel para manter a coexistência no mundo diverso e interconectado defende que a ética do discurso pode fundamentar uma macroética planetária da corresponsabilidade.

Apesar de Apel ter alertado sobre esses problemas globais há mais de 50 anos, muitos deles ainda estão presentes e tornaram-se mais graves, por exemplo, os relacionados ao meio ambiente e as mudanças climáticas. Sobre esse tema, o relatório mais recente do Painel Intergovernamental de Mudanças Climáticas², de 2014, considera que "a influência humana no sistema climático é clara, e as recentes emissões antropogênicas de gases de efeito estufa [GEE] são as mais altas da história" (IPCC, 2014, 02). A intensificação dos problemas sociais e globais que decorrem das mudanças climáticas torna extremamente urgente a busca por uma ética global. Tendo isso em vista, o objetivo deste artigo é investigar se a ética do discurso de Apel pode ser relevante e atual para lidar com as implicações éticas das mudanças climáticas. A macroética planetária irá exigir que os indivíduos se coloquem numa situação de diálogo e corresponsabilidade para o enfrentamento das mudanças climáticas. Isso exigirá cooperação internacional entre governos para reduzir equitativamente as emissões de GEE o mais rápido possível e solidariedade internacional entre comunidades para garantir políticas socialmente justas.

\section{A ética do discurso e o fundamento pragmático-transcendental}

A ética do discurso foi fundada na década de 70 por Apel e outros filósofos alemães e desenvolvida, posteriormente, com algumas transformações por Jürgen Habermas (1989). Para a fundamentação de regras morais, Habermas e Apel basearam-se no discurso argumentativo porque, para eles, a razão manifesta-se de forma linguística. A ideia básica 
da ação comunicativa é que o telos fundamental da linguagem humana é o entendimento entre possíveis falantes. Assim, o discurso argumentativo passa a ser o meio pelo qual podemos alcançar um entendimento sobre questões morais, que serão estabelecidas no interior de uma comunidade de comunicação, isto é, intersubjetivamente.

Apesar de Habermas e Apel concordarem com vários aspectos dessa teoria, eles tomam caminhos diferentes para realizar essa fundamentação. Habermas pretende fazer uma fundamentação pragmática-universal e Apel, uma fundamentação pragmática-transcendental. Apel pretende provar a priori que as regras da argumentação são autênticos princípios transcendentais (APEL, 2000a). A estratégia de Apel para fornecer fundamentos normativos recorre à estrutura transcendental do discurso argumentativo baseado em aspectos pragmáticos da linguagem que contém pressuposições indubitáveis da argumentação. Por questões de delimitação, não iremos abordar neste artigo as diferenças sobre essas fundamentações ${ }^{3}$. Todavia, pretendemos apresentar o caminho que Apel seguiu a partir da ética do discurso para justificar uma "macroética" da corresponsabilidade.

De acordo com Apel, a ética discursiva fundamentada a partir da pragmática transcendental pode dar respostas aos problemas globais de justiça e corresponsabilidade. Para fazer isso, ele mostra como a ética do discurso cumpre três tarefas inter-relacionadas caracterizando-a como uma transformação pós-metafísica da ética kantiana ${ }^{4}$. Em primeiro lugar, ela fornece um fundamento racional para sua reivindicação de validade universal sem recorrer ao tipo tradicional de fundamento (dedução, indução, abdução), mas por meio do uso de um tipo de racionalidade reflexiva-transcendental e comunicativa (APEL, 1993, 19). Em segundo lugar, a ética do discurso fornece uma base não apenas para uma ética de justiça global e solidariedade, mas também para uma ética de corresponsabilidade além da responsabilidade individual que supomos dentro de contextos funcionais de instituições ou sistemas sociais comunicativos (APEL, 1993, 19-20). Terceiro, o fundamento pragmático transcendental da ética do discurso fornece um princípio regulador para agir ou tomar decisões nas situações em que temos que mediar entre a racionalidade ética e a estratégica, que se refere à "parte $B$ " da ética (APEL, 1993, 20). A seguir, esclareceremos esta diferença que Apel traça entre a "parte A" e a "parte B" da ética.

Apel defende que há quatro pressuposições necessárias que estão implícitas na reivindicação de cada argumento para se chegar a um consenso na comunidade de comunicação ideal. São elas: 
(I) primeiro, a exigência de compartilhar um significado intersubjetivamente válido com meus parceiros;

(2) segundo, a exigência da verdade como uma reivindicação de um consentimento virtualmente universal;

(3) terceiro, a exigência de veracidade ou sinceridade de meus atos de fala tomados como expressões de minhas intenções;

(4) quarto, a exigência da correção moralmente relevante de meus atos de fala, tomados como ações comunicativas no sentido mais amplo de abordar possíveis parceiros de comunicação (APEL, 1993, 21, [tradução nossa]) $)^{5}$.

Para Apel, a quarta afirmação é a mais importante porque implica uma ética da comunidade ideal de comunicação. É isso o que ele chama de "parte $A$ " da ética do discurso.

Há também a "parte $B$ " que será derivada e introduzida como uma resposta ao fato de que a comunidade de comunicação ideal não existe como tal no mundo real, mas é uma antecipação contrafactual e um princípio regulador. Apel afirma que "a ética de comunicação ideal implica que todos os parceiros possíveis têm direitos iguais e igual corresponsabilidade pela e na resolução de todos os problemas possíveis que o mundo da vida poderia representar para a comunidade do discurso" (APEL, 1993, 22). Diante disso, alguém pode perguntar: "Por que devo ser moral, por exemplo, assumir a corresponsabilidade? Existe um bom motivo - ou seja, um fundamento racional - para isso?" Apel responde afirmativamente:

sim, se você está perguntando seriamente, então, você tem a resposta. Pois, você pode descobrir por meio de uma reflexão radical sobre os pressupostos da sua ação que você já assumiu a corresponsabilidade no nível do discurso argumentativo e, portanto, reconheceu as normas fundamentais da comunidade de comunicação ideal que delineei: de direitos iguais e corresponsabilidade (APEL, 1993, 22).

Aqui, podemos identificar a derivação da norma fundamental de corresponsabilidade a partir da reflexão transcendental-pragmática. Todavia, ele observa que a corresponsabilidade pode gerar um sentimento de impotência e que poderia paralisar o indivíduo "que tenta assumir, de forma responsável, a imputabilidade pelo que temos que iniciar e organizar coletivamente para enfrentar os fenômenos das crises globais" (APEL, 1993, 23). Ele explica isso do ponto de vista da ética do discurso: "No nível do 
discurso argumentativo, que é de fato o nível metainstitucional em relação a todas as instituições", cada membro da comunidade argumentativa "reconheceu uma espécie de responsabilidade - ou melhor, corresponsabilidade - que a priori nos une através do alicerce de uma solidariedade original com todos os demais membros possíveis da comunidade argumentativa" (APEL, 1993, 24). Esta solidariedade original de corresponsabilidade alivia as pessoas da sobrecarga individual, sem permitir que se esquivem de sua parte de responsabilidade por meio do escapismo. Pode-se perceber que a ética do discurso de Apel, na sua "parte $\mathrm{B}^{\prime \prime}$, exige a corresponsabilidade de todos aqueles que pertencem a uma comunidade real e vai muito além da ideia tradicional de responsabilidade individual.

Uma questão que precisa ser feita aqui é esta: como se pode conceber a transferência da corresponsabilidade originária por meio de discursos práticos para a solução dos problemas concretos, como as mudanças climáticas, a fome e a crise ecológica? De acordo com Apel, a tarefa de organizar discursivamente e praticar a corresponsabilidade por ações complexas deve ser cumprida pela "crescente rede mundial de diálogos formais ou informais e conferências, comissões e conselhos em todos os níveis da política nacional e especialmente internacional, incluindo, é claro, a política econômica, cultural e educacional" (APEL, 1993, 24). Ele explica que a função desses meios de organizar discursivamente a responsabilidade coletiva da humanidade nada mais é do que uma "generalização e projeção da função da democracia - na medida em que a democracia em sua essência pode ser fundamentada pela ética do discurso" (APEL, 1993, 24). Algumas reflexões sobre a implementação da ética do discurso de Apel podem ser realizadas aqui. Como podemos perceber, a ética do discurso exige que discursos práticos reais sejam realizados e também revela a necessidade de uma esfera pública planetária. De acordo com alguns comentadores,

esta esfera pública planetária [Welt Offenlichkeit], já parcialmente atualizada na forma das Nações Unidas, a Corte Mundial [Corte Internacional de Justiça], e os inúmeros movimentos sociais transnacionais e transcontinentais com agendas feministas, ecológicas e econômicas, é o lugar das discussões contemporâneas que levam à implementação de uma ética planetária de corresponsabilidade pelos efeitos de nossas ações no mundo (MENDIETA, 1996, xv, [tradução nossa]).

Assim, a corresponsabilidade pelas consequências de nossas ações coletivas implica a institucionalização de um discurso global que deve 
envolver os indivíduos que não necessariamente tem responsabilidade causal, mas que contribuem e possivelmente serão afetados por problemas globais.

A partir da próxima seção, tentaremos extrair respostas que a ética do discurso, enquanto macroética planetária, orientada pela corresponsabilidade, pode oferecer aos principais problemas que surgem com as mudanças climáticas.

\section{Implicações éticas das mudanças climáticas}

As mudanças climáticas de origem antropogênica representam um dos principais desafios éticos que a humanidade enfrenta atualmente. 0 Painel Intergovernamental de Mudanças Climáticas (IPCC, 2014) e vários estudos publicados em revistas acadêmicas defendem a necessidade de se chegar a um consenso científico sobre os efeitos que já estão ocorrendo. Dentre eles, pode-se destacar: os padrões de precipitações estão alterados (IPCC, 2014); as geleiras e as camadas de gelo estão derretendo mais rapidamente (IPCC, 2014); aumento na temperatura média global da superfície da Terra (NASA, 2019); a acidificação dos oceanos (NOAA); os níveis do mar estão aumentando e as inundações costeiras estão mais frequentes, severas e persistentes (KOPP et al., 2016).

As previsões dos efeitos colaterais das mudanças climáticas afetam não apenas o tempo, os animais não-humanos e os sistemas ecológicos, mas podem causar danos diretamente aos seres humanos e seus meios de subsistência. À medida que o nível do mar sobe, as terras nas planícies costeiras serão inundadas e as ilhas baixas poderão ficar totalmente submersas. As mudanças nos padrões de chuvas irão tornar a agricultura não praticável em muitas áreas $e$, consequentemente, promover a insegurança alimentar; as tempestades de maior magnitude, o aumento das enchentes e elevações de temperaturas colocam as pessoas em todo o mundo em risco (IPCC, 2014).

Esses efeitos nocivos aumentam os problemas relacionados às desigualdades econômicas e justiça social, pois trazem consequências negativas principalmente aos mais desfavorecidos. $O$ relatório $A s$ desigualdades extremas das emissões de carbono, publicado pela Oxfam, em 2015, defende que a metade da população mais pobre do mundo será a mais ameaçada pelas tempestades, secas e outros eventos provocados pela mudança do clima. Contudo, ela é a responsável por apenas $10 \%$ das emissões de carbono. Os $10 \%$ dos países mais ricos produzem metade das emissões mundiais (OXFAM, 2015, 01). Por conta disso, alguns filósofos (cf. CANEY, 2005; SHUE, 2014) chamam atenção para o fato de que o impacto 
das atividades antropogênicas levanta questões de justiça global, de respeito aos direitos humanos além de colocar sérias ameaças à biodiversidade.

Como se pode perceber, as mudanças climáticas geram vários efeitos que são considerados desafios altamente complexos. Para explicar mais claramente os principais desafios que surgem com eles, alguns especialistas, por exemplo, Stephen Gardiner (2011, 23-4), comparam a mudança do clima à "tempestade moral perfeita".

O primeiro desafio decorre do fato de que a mudança climática é um problema global, pois atinge escalas globais. O número de pessoas envolvidas é muito maior do que em um problema ético individual ou local. Uma vez que as emissões de GEE são lançadas, elas podem ter impactos em qualquer lugar do planeta, independentemente de sua fonte de origem. Elas não respeitam "fronteiras nacionais". Na ética, isso pode resultar no problema conhecido por "tragédia dos comuns" (HARDIN, 1968). Embora coletivamente todos os países prefiram limitar as emissões globais, a fim de reduzir o risco de impactos graves ou catastróficos e proteger o bem comum, individualmente cada um prefere continuar a emitir GEE sem impedimentos. Assim, as mudanças climáticas podem gerar vulnerabilidades assimétricas: os países e as pessoas mais vulneráveis são os que menos emitiram historicamente e seus níveis de emissões continuam relativamente baixos. Isso parece ser injusto e reforça a necessidade de unirmos esforços práticos para garantir a cooperação global. Como vimos na seção anterior, sobre o problema de ação coletiva, a ética do discurso de Apel tem uma posição clara, a saber, a defesa das responsabilidades compartilhadas: "pela primeira vez, aos poucos foi ficando claro que, pelo menos no que diz respeito à nossa ecoesfera, somos compelidos a organizar, de alguma forma, um senso coletivo de responsabilidade pelas consequências de nossas atividades em ciência e tecnologia" (APEL, 1996, 278, [tradução nossa]). Dada as características específicas dos problemas de ação coletiva, Apel considera a necessidade de implementar a macroética planetária. Nas palavras dele:

verifica-se que em ambas as dimensões da evolução cultural, nomeadamente, a das intervenções tecnológicas na natureza e a da interação social, se desenrolou no nosso tempo uma situação global que exige uma nova ética da responsabilidade partilhada, ou seja, para um tipo de ética que, em contraposição às formas tradicionais ou convencionais de ética, pode ser denominada macroética (planetária) (APEL, 1996, 278, [tradução nossa]). 
O segundo desafio é que as emissões atuais têm efeitos intergeracionais. As emissões do gás de efeito estufa mais comum, a saber, o dióxido de carbono $\left(\mathrm{CO}_{2}\right)$, normalmente permanecem na atmosfera por um longo período de tempo, contribuindo com as mudanças por séculos (IPCC, 2014). Se os impactos futuros dessas emissões forem graves e cumulativos estamos diante de uma situação em que as gerações anteriores podem afetar diretamente as gerações futuras. Essa característica distintiva da mudança climática nos força a analisar como obter uma distribuição justa do ônus do combate às mudanças climáticas antropogênicas, levando em consideração não apenas as dimensões globais, mas também as intergeracionais. Sobre esse aspecto, vimos anteriormente que a ética do discurso de Apel se preocupa com a incapacidade que o sistema ocidental tem de estabelecer uma responsabilidade ética solidária da humanidade em face do risco colocado pela racionalidade científico-tecnológica. Especificamente, em relação as gerações futuras, Apel afirma:

Para as decisões, convenções e acordos de pessoas que estão apenas se esforçando para alcançar compromissos de interesse - ou seja, não se esforçando para mediar argumentativamente todos os interesses das pessoas afetadas de acordo com as normas éticas - essas decisões, convenções e acordos não podem, em princípio, fornecer uma base, por exemplo, para uma solução justa de conflitos digamos, aqueles entre os países industriais avançados e 0 terceiro ou quarto mundo, ou aqueles entre os vivos e as gerações futuras da humanidade que parecem constituir o núcleo moralmente relevante da chamada 'crise ecológica' (APEL, 1996, 142).

Pode-se sustentar, então, que a atitude de corresponsabilidade também levaria em consideração os interesses das futuras gerações. É necessário assim que todos os Estados, indivíduos, corporações cooperem para limitar efetivamente emissões de GEE, de modo a desacelerar, interromper ou mesmo reverter a mudança climática global e favorecer as futuras gerações.

O terceiro desafio à ação ética é que nossas ferramentas teóricas não estão desenvolvidas em muitas das áreas relevantes, a saber, a justiça internacional e a ética intergeracional. Falta estabelecer estruturas institucionais para administrar problemas de ação coletiva em escalas globais e não temos conceitos desenvolvidos para lidar com as obrigações para com as gerações futuras. A mudança climática é um problema global em um mundo sem uma autoridade política internacional plenamente capaz 
de administrá-lo. Há uma série de documentos internacionais que podem ser usados para articular um consenso internacional existente sobre os valores éticos que devem orientar nossas respostas às mudanças climáticas globais. Dentre os principais podemos citar: A Convenção-Quadro das Nações Unidas sobre Mudança do Clima, 1992; A Declaração Universal sobre Bioética e Direitos Humanos (UDBHR), 2005; o Acordo de Paris, $2015^{6}$. A ONU é uma instituição muito importante, mas não possui poder suficiente para aplicar efetivamente uma política global sobre as emissões de $\mathrm{CO}_{2}$. Para ilustrar isso, podemos citar o Protocolo de Quioto, que foi adotado em 1997, mas só entrou em vigor em 2005. Os Estados Unidos, o maior emissor mundial de gases de efeito estufa daquele momento (atualmente, o segundo maior poluidor), assinou mas não ratificou o Protocolo e alegou que a implantação das metas propostas pelo acordo prejudicariam a economia do país. Isso tornou as negociações mais extensas, pois $55 \%$ dos países do Anexo I (que incluía os países desenvolvidos) precisaram ratificar o Protocolo.

O não cumprimento das corresponsabilidades também já está acontecendo em relação ao Acordo de Paris. Por exemplo, o Brasil apresentou na $21^{\text {a }}$ Conferência das Partes (COP21) da UNFCCC ${ }^{7}$, as contribuições nacionalmente determinadas (NDCs) comprometendo-se, entre outras coisas, a 1) promover uma redução de suas emissões de GEE em 37\% abaixo dos níveis de 2005 até 2025; e 2) reflorestar 12 milhões de hectares até 2030 (NDC, 2015). Infelizmente, estamos indo na direção contrária: dados do Instituto Nacional de Pesquisas Espaciais (INPE) mostram que 830 quilômetros quadrados $(\mathrm{km} 2)$ de floresta tropical foram desmatados na "Amazônia Legal" em maio de 2020, elevando o desmatamento total desde $1^{0}$ de agosto para $6.437 \mathrm{~km}^{2}$. Uma parte substancial desse desmatamento ilegal está ligada a produção de commodities agrícolas de exportação. Há relatos de queda no investimento, e consumidores e investidores internacionais levantaram questões sobre a política ambiental do país: "Os compradores internacionais de commodities agrícolas brasileiras têm se preocupado com produtos que estão contaminados pelo desmatamento (ou seja, o desmatamento ocorrido durante o processo de produção do produto)" (RAJÃo et al., 2020, 246). Sendo assim, enquanto um regime global legalmente vinculante para limitar as emissões não for realmente implementado, ficamos diante do desafio de como estabelecer novos procedimentos discursivos que facilitariam a tomada de decisão global através da ONU. 


\section{Corresponsabilidade nas políticas de mitigação, adaptação e emissão}

Nesta seção, iremos investigar como a corresponsabilidade pode ser empregada para enfrentar as mudanças climáticas. De modo geral, podemos distinguir entre pelo menos três tipos diferentes de responsabilidades em relação ao clima (CANEY, 2010a). Primeiro, pode-se dizer que há o dever de reduzir as atividades que causam as mudanças climáticas. Esse tipo de obrigação pode ser chamado de "dever de mitigação" (CANEY, 2010b, 204). Ele exige que as pessoas se envolvam em ações de "mitigação". As obrigações incluiriam, por exemplo, um dever de reduzir as emissões de GEE, principalmente, as emissões de dióxido de carbono. Na prática, isso exigiria que as pessoas adotassem políticas como reduzir as viagens aéreas, usar menos os automóveis, usar menos eletricidade, optar, se possível, por utilizar energias renováveis e limpas, criar e proteger sumidouros de carbono, i.e., reflorestar e impedir o desmatamento das florestas.

O segundo tipo de responsabilidade é a de destinar recursos para proteger as pessoas dos efeitos nocivos das mudanças climáticas que já estão ocorrendo. Isso implica em facilitar e apoiar a "adaptação" às mudanças climáticas e possibilitar que as pessoas vivam diante dessas mudanças. Essa responsabilidade envolve o investimento em diferentes atividades, por exemplo: a construção de infraestruturas (por exemplo, muros de contenção) para proteger populações costeiras e que serão prejudicadas com o aumento do nível do mar e tempestades; subsidiar as pessoas a se afastarem dos assentamentos costeiros ameaçados; usar recursos para prevenir doenças infecciosas; apoiar sistemas de irrigação em áreas propensas a secas; ajudar as vítimas de desnutrição; desenvolver sementes resistentes às secas e assim por diante.

Terceiro, há também os deveres de compensação, a saber, compensar aqueles que foram prejudicados com os efeitos da mudança do clima. Um ponto importante que deve ser destacado é que os custos de adaptação às mudanças climáticas são maiores do que os custos de mitigar as emissões. Apesar de um apoio maior ser dado às ações de mitigação, também é amplamente reconhecido que ações de adaptação são necessárias. A emissão de gases de efeito estufa vem ocorrendo desde a Revolução Industrial e mesmo que os níveis de emissões fossem drasticamente reduzidos ainda teríamos os seus efeitos acontecendo.

Pode parecer óbvio que os seres humanos existentes devam assumir as principais responsabilidades, pois são os únicos agentes que podem fazer algo para mitigar as emissões ou adotar políticas que gerenciem a adaptação dos impactos que não são mais evitáveis. No entanto, há 
diferentes entidades que podem assumir as corresponsabilidades perante as mudanças climáticas, a saber, os países, as organizações supranacionais, as corporações nacionais e multinacionais, instituições internacionais e nacionais e, de modo mais abstrato, a atual geração como um todo.

Como sabemos, a COP 21 aprovou, em dezembro de 2015, o Acordo de Paris que determina "manter o aumento da temperatura média global a menos de 2 graus Celsius acima dos níveis pré-industriais" (ONU, 2015). Em relação aos deveres de mitigação e adaptação, o Acordo de Paris defende, em seu Artigo $2^{\circ}$, que ele será implementado " 2 . para refletir a igualdade e o princípio das responsabilidades comuns, porém diferenciadas e respectivas capacidades, à luz das diferentes circunstâncias nacionais". (ONU, 2015, Art. 2). Ele é conhecido como o princípio das responsabilidades comuns, porém diferenciadas (PRCPD) e já era adotado pelo Protocolo de Quioto. A principal diferença agora é que no Acordo de Paris não se considerada mais a divisão de responsabilidades entre países desenvolvidos e em desenvolvimento (países do Anexo I e Anexo II). Para estabilizar a temperatura global, todos os emissores mais altos, incluindo os países desenvolvidos e os países em desenvolvimento (como China, Índia e Brasil) devem contribuir.

$\mathrm{O}(\mathrm{a}) \mathrm{s}$ filósofo(a)s que trabalham com as mudanças climáticas geralmente têm apoiado o princípio das responsabilidades comuns, porém diferenciadas devido a três argumentos principais: 1) historicamente, os países industrializados contribuíram mais para a mudança do clima e, em uma base per capita, continuam a contribuir mais; 2) os países industrializados têm a maior capacidade de pagar pela mitigação e adaptação ao clima; 3) as nações industrializadas se beneficiaram mais das emissões de GEE, enquanto as nações menos desenvolvidas estão tendo (e continuarão a suportar) grande parte dos impactos climáticos. (SHUE, 2001, 457; HOURDEQUIN, 2015, 158). Como pode-se perceber, o PRCPD se compromete com a corresponsabilidade e, desse modo, seria amparado pela macroética planetária.

A maioria dos líderes mundiais reunidos em Paris concordam com o objetivo de limitar as emissões. Mas há uma série de divergências sobre quem deve ser responsável pelas despesas e compromisso de reduzir os poluentes. A busca pela redução de custos na produção industrial tem levado os países ricos a terceirizar as emissões de GEE para os países em desenvolvimento. Países como China (atualmente, o maior poluidor) e Índia estão queimando combustíveis e fazendo altas emissões para produzir bens para consumidores norte-americanos, europeus e outras economias e não apenas para seu consumo interno. No caso do Brasil, a Floresta Amazônica, que possui um papel crucial na mitigação das mudanças climáticas, está 
ameaçada pelo desmatamento, principalmente para a criação de gado e para a produção de soja (HEINRICH BÖLL FOUNDATION, 2015, 15-20). Diante disso, pode-se levantar as seguintes perguntas: quais responsabilidades os consumidores e empresas que compram carne bovina e soja brasileira devem assumir perante as mudanças climáticas? A terceirização de produção deveria diminuir a responsabilidade dos países ricos em relação aos impactos ambientais de seus hábitos de consumo? Como pensar no desenvolvimento de políticas de emissões de GEE e como colocá-lo em prática com justiça?

O problema global da crise ecológica e sua relação com o subdesenvolvimento econômico dos países da América Latina (e de outros denominados na época de países do "Terceiro Mundo") foram temas abordados por Apel ${ }^{8}$. No artigo A Planetary Macroethics for Humankind, ao comentar sobre os problemas da crise ecológica global, Apel afirma:

Assim, descobrimos que nós, no mundo desenvolvido, somos agora confrontados, em nossa relação com o meio ambiente, com as mesmas novas - e quase ultrajantes - demandas morais que nos confrontamos em nossas interações econômicas de longa distância com as pessoas. Espera-se agora que cada um de nós compartilhe pelo menos alguma responsabilidade pelas emissões de plantas industriais na atmosfera e na água, ou pela preservação das florestas em escala global, pelo próprio clima e atmosfera de todo o planeta, e ao mesmo tempo, cada um de nós deve se sentir responsável como cidadão - por exemplo, como leitor de um jornal ou como eleitor - pela política, digamos, do Banco Mundial com relação à dívida do Terceiro Mundo (APEL, 1996, 278, [itálicos acrescentados]).

Vejamos, agora, o que poderia ser exigido pela macroética planetária diante de problemas ecológicos, tais como, as mudanças climáticas, e as relações entre países desenvolvidos e em desenvolvimento diante desse problema.

Em primeiro lugar, os países são frequentemente considerados os únicos responsáveis pelos deveres de mitigação e adaptação. Isso ocorre porque os tratados internacionais como o Protocolo de Quioto, a Convenção-Quadro da UNFCCC e o Acordo de Paris (2015) estabelecem requisitos que devem ser adotados pelos países através de suas legislações. Uma das consequências de se assumir a corresponsabilidade $e$ a solidariedade é que os deveres não irão recair apenas sobre os estados, mas também sobre todos os cidadãos. Muitos agentes, para além dos governos nacionais, devem assumir um papel de responsabilidade, 
nomeadamente, indivíduos, empresas e autoridades políticas. Assim, considerando o caso brasileiro, podemos argumentar que todos os parceiros econômicos do Brasil devem compartilhar as responsabilidades por promover indiretamente o desmatamento e as emissões de GEE que irão agravar os efeitos das mudanças climáticas. $O$ atual sistema de produção alimentar global que inclui o uso do solo na agricultura, a fabricação de fertilizantes, o armazenamento e a produção embalagem de alimentos, é responsável por um quarto de todas as emissões de GEE que causam as mudanças climáticas. Então, como indivíduos e como sociedade global, o que decidimos comer é crucial para lidar com as mudanças climáticas. De acordo com um relatório do Greenpeace, o consumo global de carne e laticínios deve ser cortado pela metade até 2050 para evitar mudanças climáticas perigosas e manter o Acordo de Paris (GREENPEACE, 2018). O dever de pagar por medidas de adaptação e investir em mitigação deve ser maior para aqueles cuja riqueza surgiu de forma injusta, por exemplo, aqueles que se beneficiaram do desmatamento ilegal. Empresas e comerciantes de commodities devem rastrear sua cadeia de suprimentos para monitorar os compromissos de desmatamento zero e financiar a restauração florestal.

Em segundo lugar, podemos defender através do princípio de solidariedade que os mais favorecidos têm maior responsabilidade e liderança nas políticas de mitigação, reparação e adaptação. Mas isso não significa que os menos favorecidos não tenham deveres. Se os menos favorecidos podem se desenvolver de uma maneira que não requeira altos níveis de uso de combustíveis fósseis, e podem fazê-lo sem grandes custos para si mesmos, então seria errado para eles seguirem uma política de altas emissões. O Brasil é considerado o país com maior biodiversidade do mundo, com vastas florestas, recursos hídricos, reservas minerais. No entanto, sua economia está enfraquecendo e as disparidades de renda continuam altas. De acordo com a OECD (2015), o Brasil possui uma estrutura legislativa abrangente e avançada para a gestão ambiental e o uso sustentável da biodiversidade. O novo Código Florestal do país (BRASIL, 2012) promete conciliar os objetivos de conservação da biodiversidade e desenvolvimento agrícola, e conta com sistemas de monitoramento de desmatamento de primeira linha. O que ele precisa, agora, é de vontade política para permanecer vigilante e tomar medidas concretas para implementar integralmente todos os programas ambientais para reduzir o desmatamento.

Terceiro, deve-se ressaltar aqui que as ligações entre as florestas tropicais, por exemplo, a Floresta Amazônica e os interesses das gerações futuras são claras. As florestas desempenham um papel vital na regulação 
do clima da Terra e são as nossas melhores defesas contra as mudanças climáticas. De acordo com estudos recentes, já há evidências para afirmar que a perda da Floresta Amazônica é um ponto de inflexão, ou seja, um elemento do sistema terrestre que está passando por mudanças repentinas e potencialmente irreversíveis (NOBRE, 2019). Essa crescente ameaça deve ser considerada nas ações políticas e econômicas para reduzir as emissões de GEE, pois "O desmatamento e as mudanças climáticas estão desestabilizando a Amazônia (...). As estimativas de onde um ponto crítico na Amazônia poderia estar variam de $40 \%$ de desmatamento a apenas $20 \%$ de perda de cobertura florestal. Cerca de $17 \%$ foram perdidos desde 1970" (LENTON et al., 2019). A crescente ameaça de mudanças climáticas abruptas e seus efeitos irreversíveis devem obrigar imediatamente a uma ação política e econômica sobre as emissões e o desmatamento. Além disso, essas ações devem respeitar as terras e os direitos dos povos indígenas e das gerações futuras.

\section{Conclusão}

Neste artigo, analisamos como Karl-Otto Apel implementa a ética do discurso como uma macroética planetária e como ela pode ser aplicada para abordar os problemas éticos que surgem com as mudanças climáticas. Verificamos que a macroética planetária exige uma situação de diálogo e corresponsabilidade para enfrentar os efeitos das mudanças climáticas. Isso exige cooperação internacional entre governos, mas também entre indivíduos, empresas, corporações para reduzir equitativamente as emissões de GEE o mais rápido possível e garantir políticas socialmente justas. O enfrentamento das mudanças climáticas exige ações de corresponsabilidades globais urgentes que envolvam os diferentes agentes individuais e institucionais, principalmente, para fazer uma transição para uma economia livre de carbono e para promover o desenvolvimento sustentável. Para isso ser feito, é necessário que essa transição seja justa e que os encargos exigidos possam ser assumidos pelos diferentes agentes responsáveis. Nesse sentido, podemos afirmar que as implicações da macroética planetária são relevantes e atuais para lidar com as implicações éticas das mudanças climáticas. 


\section{Notas}

1 Professora Associada II no Departamento de Filosofia e no Programa de Pósgraduação em Filosofia da Universidade Federal de Santa Catarina (UFSC), Santa Catarina (S.C.), Brasil. E-mail: milene.consenso.tonetto@ufsc.br

Gostaria de agradecer aos pareceristas anônimos da Revista ethic@ pelos comentários, críticas e sugestões.

2 O Painel Intergovernamental de Mudanças Climáticas (ou IPCC, na sigla em inglês) é o principal órgão internacional que sintetiza e avalia todo o conhecimento e todas as informações revisadas por pares (i.e., por especialistas no assunto) e publicadas sobre a mudança no clima (IPCC, 2014).

3 Sobre as diferenças entre Apel e Habermas ver: (VOLPATO DUTRA, 2005; VELASCO, 2001).

4 A fundamentação da moral proposta por Immanuel Kant (KANT, 1986) foi criticada, principalmente, por ser meramente formal (HEGEL, 2003, §135) e por basear-se exclusivamente em regras negligenciando o papel do caráter e das virtudes (MacINTYRE, 1981, p. 119), e levou a várias tentativas de reformulação. Uma delas foi a ética discursiva.

${ }^{5}$ As citações diretas das seguintes obras de Apel foram traduzidas pela autora: 1) How to ground a universalistic ethics of co-responsibility for the effects of collective actions and activities? (APEL, 1993); 2) A planetary Macroethics for Humankind: The need, the apparent difficulty, and the eventual possibility (APEL, 1996); 3) Introduction (MENDIETA, 1996).

6 Outros documentos relacionados: A Declaração Universal dos Direitos Humanos (UDHR), 1948; A Convenção das Nações Unidas sobre Diversidade Biológica, 1992; a Declaração da UNESCO sobre as Responsabilidades das Gerações Atuais em Relação às Gerações Futuras, 1997; A Carta da Terra, 2000, reconhecida pela Conferência Geral da UNESCO.

7 UNFCCC, sigla em inglês para Nations Framework Convention on Climate Change (Convenção-Quadro das Nações Unidas sobre a Mudança do Clima). Os países membros da Convenção reúnem-se periodicamente nas Conferências das Partes (COP, na sigla em inglês). A $21^{\text {a }}$ Conferência das Partes (COP 21) também é conhecida por Conferência do Clima de Paris.

8 Essas preocupações colocaram Apel no debate com os filósofos latinoamericanos, por exemplo, Enrique Dussel. Conferir: (DUSSEL, 1993). 


\section{Referências bibliográficas}

APEL, Karl-Otto. How to ground a universalistic ethics of co-responsibility for the effects of collective actions and activities? Philosophica. 52 (1993, 2) pp. 9-29.

APEL, Karl-Otto. "A Planetary Macroethics for Humankind: The need, the apparent difficulty, and the eventual possibility". In: MENDIETA, E (ed.). Karl-Otto Apel: selected essays. Ethics and theory of rationality. (vol. 2). Humanities Press: New Jersey, 1996.

APEL, K. O. Transformação da filosofia [Tomo I e II]. Edições Loyola: São Paulo, 2000a.

APEL, Karl-Otto. Globalization and the Need for Universal Ethics. European Journal of Social Theory May 1, 2000b. https://doi.org/10.1177/13684310022224732

BRASIL. Lei no 12.651, de 25 de maio de 2012. Dispõe sobre a proteção da vegetação nativa. Brasília, 2012. Disponível em: <http://www.planalto.gov.br/ccivil_03/_ato20112014/2012/lei/l12651.htm>

CANEY, Simon. Cosmopolitan Justice, Responsibility, and Global Climate Change. Leiden Journal of International Law, Cambridge, vol. 18, p. 747775, 2005.

CANEY, Simon. Climate Change, Human Rights e Moral Threshold. In: GARDINER, S. et al. Climate ethics: essential readings. Oxford: Oxford University Press, 2010a. p. 163-177.

CANEY, Simon. Climate Change and the Duties of the Advantaged. Critical Review of International Social and Political Philosophy, vol. 13, p. 203-228, 2010b.

CANEY, Simon. Climate Change. In: Moellendorf, D. \& Widdows, H. The Routledge Handbook of Global Ethics. Abingdon, Oxon: Routledge, 2015. p. 372-386.

DIAS, Maria Clara. Os direitos sociais básicos: uma investigação filosófica da questão dos direitos humanos. Porto Alegre: EDIPUCRS, 2004.

DUSSEL, Erinque. Apel, Ricoeur, Rorty y la Filosofía de la liberación. México: Ediciones de la Universidad de Guadalajara, 1993. Disponível em: $<$ https://www.enriquedussel.com/txt/Textos_Libros/47.Apel_Ricoeur_Rort y_f.liberacion.pdf> 
GARDINER, Stephen M. A perfect moral storm: the ethical tragedy of climate change with a new afterword. New York: Oxford University Press, 2011.

GREENPEACE INTERNATIONAL. "Greenpeace calls for decrease in meat and dairy production and consumption for a healthier planet", 2018. Available at:

$<$ https://www.greenpeace.org/international/pressrelease/15111/greenpeace-calls-for-decrease-in-meat-and-dairyproduction-and-consumption-for-a-healthier-planet/> $27 / 07 / 2020$.

HABERMAS, J. Consciência moral e agir comunicativo. Rio de Janeiro, Tempo Brasileiro, 1989. p.78.

HARDIN, Garrett. The Tragedy of the Commons, The Social Contract, Fall 2001 p. 26-35. Disponível em: <https://www.garretthardinsociety.org/articles_pdf/tragedy_of_the_com mons.pdf>

HEGEL, F. Princípios da filosofia do direito. São Paulo: Martins Fontes, 2003.

HEINRICH BÖLL FOUNDATION. Atlas da carne: fatos e números sobre os animais que comemos. Rio de Janeiro: Heinrich Böll Foundation, 2015.

HOURDEQUIN, Marion. Environmental Ethics. From theory to practice. London: Bloomsbury Academic, 2015.

INPE. A estimativa da taxa de desmatamento por corte raso para a Amazônia Legal em 2019 é de $9.762 \mathrm{~km}^{2}$. 18 Nov. 2019. Disponível em: <http://www.inpe.br/noticias/noticia.php?Cod_Noticia=5294>. Acessado: 19 nov. 2019.

IPCC, 2014: Climate Change 2014: Impacts, Adaptation, and Vulnerability. Summaries, Frequently Asked Questions, and Cross-Chapter Boxes. A Contribution of Working Group II to the Fifth Assessment Report of the Intergovernmental Panel on Climate Change [Field, C.B., et all (eds.)]. World Meteorological Organization, Geneva, Switzerland, 190 pp. Disponível em: <https://www.ipcc.ch/report/ar5/wg2/>

LENTON, Timothy M. et al. Climate tipping points - too risky to bet against. Nature 575, 592-595 (2019) doi: 10.1038/d41586-019-03595-0

KANT, I. Fundamentação da Metafísica dos Costumes. Lisboa: Edições 70, 1986.

KOOP, R. E. et all. Common Era global sea-level variability Proceedings of the National Academy of Sciences Mar 2016, 113 (11) E1434-E1441; DOI: $10.1073 /$ pnas. 1517056113 
MacINTYRE, A. After virtue: a study in moral theory. London: Duckworth, 1981.

MENDIETA, E. "Introduction". In: MENDIETA, E (ed.). Karl-Otto Apel: selected essays. Ethics and theory of rationality. (vol. 2). Humanities Press: New Jersey, 1996. p. xi-xxii.

NASA. Climate Change: Vital Signs of the Planet. Disponível em: https://climate.nasa.gov/. Acessado em: 30/11/2020.

NDC. Pretendida Contribuição Nacionalmente Determinada Para Consecução do Objetivo da Convenção-Quadro das Nações Unidas Sobre Mudança do Clima. República Federativa do Brasil, 2015. 10 pp. Disponível em:

<https://www.mma.gov.br/images/arquivos/clima/convencao/indc/BRASI L_iNDC_portugues.pdf > . Acessado em: 05/10/2020.

NOAA. What is Ocean Acidification? Disponível em: https://oceanservice.noaa.gov/facts/acidification.html. Acessado em: 28/11/2020.

NOBRE, Carlos A. To save Brazil's rainforest, boost its science. Nature 574, 455 (2019) doi: 10.1038/d41586-019-03169-0

OECD. 2015. Environmental Performance Reviews: Brazil 2015. Available at: < https://read.oecd-ilibrary.org/environment/oecd-environmentalperformance-reviews-brazil-2015_9789264240094-en\#page11>. DOI: http://doi.org/10/8bn

ORGANIZAÇ̃̃̃O DAS NAÇ̃̃̃ES UNIDAS (ONU). Declaração Universal dos Direitos humanos. 1948. Disponível em: < https://www.ohchr.org/en/udhr/documents/udhr_translations/por.pdf > Acesso em: 11/10/2020.

ORGANIZAÇ̃̃O DAS NAÇ̃̃ES UNIDAS (ONU). Convenção sobre Diversidade Biológica. $\quad$ Disponível em: <http://www.mma.gov.br/estruturas/sbf_dpg/_arquivos/cdbport.pdf> Acesso em: 11/10/2020.

ORGANIZAÇ̃̃O DAS NAÇÕ̃ES UNIDAS (ONU). O futuro que queremos. 2020. Disponível em: <https://riomais20sc.ufsc.br/files/2012/07/CNUDSversão-português-COMITÊ-Pronto1.pdf> Acesso em: 11/10/2020.

ORGANIZAÇ̃̃̃O DAS NAÇ̃̃ES UNIDAS (ONU). Acordo de Paris. 2015. Disponível em: <http://www.mpf.mp.br/atuacao-tematica/sci/normas-elegislacao/tratados/convencoes-meio-ambiente/acordo-de-paris.pdf/view > Acesso em: 11/10/2020. 
ORGANIZAÇ̃̃O DAS NAÇÕES UNIDAS (ONU). Carta da Terra. Disponível em: https://www.mma.gov.br/responsabilidade-socioambiental/agenda21/carta-da-terra

Acesso em: 11/10/2020.

OXFAM. Extreme Carbon Inequality. Why the Paris climate deal must put the poorest, lowest emitting and most vulnerable people first. 2015. Available at: https://www.oxfam.org/sites/www.oxfam.org/files/file_attachments/mbextreme-carbon-inequality-021215-en.pdf

RAJÃO, R. et al., "The rotten apples of Brazil's agribusiness," Science, vol. 369 , issue 6501, 17 July 2020.

SHUE, Henry. Subsistence Emissions and Luxury Emissions. In: Climate Justice Vulnerability and Protection. Oxford: Oxford University Press, 2014, p. 46-67.

TUGENDHAT, E. Lições sobre ética. Petrópolis, Rio de Janeiro: Vozes, 1996.

UNESCO. Declaração sobre as Responsabilidades das Gerações Presentes em Relação às Gerações Futuras. 1997. Disponível em: $<$ http://mapacultural.es.gov.br/files/agent/27797/declaracao_responsabil diade_geracoes_presentes_geracoes_futuras.pdf $>$ Acesso em: $11 / 10 / 2020$.

VOLPATO DUTRA, D. Razão e consenso em Habermas. A teoria discursiva da verdade, da moral, do direito e da biotecnologia. Florianópolis: Editora da UFSC, 2005. 